\title{
Increased PD-1-positive macrophages in the tissue of gastric cancer are closely associated with poor prognosis in gastric cancer patients
}

\author{
Yusuke Kono ${ }^{1}$, Hiroaki Saito ${ }^{2 *}$, Wataru Miyauchi ${ }^{1}$, Shota Shimizu ${ }^{1}$, Yuki Murakami ${ }^{2}$, Yuji Shishido ${ }^{1}$, Kozo Miyatani $^{1}$, \\ Tomoyuki Matsunaga' ${ }^{1}$, Yoji Fukumoto ${ }^{1}$, Yuji Nakayama ${ }^{3}$, Chiye Sakurai ${ }^{4}$, Kiyotaka Hatsuzawa ${ }^{4}$ and \\ Yoshiyuki Fujiwara'
}

\begin{abstract}
Background: Programmed cell death 1 (PD-1) is one of the immune checkpoint molecules that negatively regulate the function of T cells. Although recent studies indicate that PD-1 is also expressed on other immune cells besides T cells, its role remains unclear. This study aims to evaluate PD-1 expression on macrophages and examine its effect on anti-tumor immunity in gastric cancer (GC) patients.

Methods: The frequency of PD- $1^{+}$macrophages obtained from GC tissue was determined by multicolor flow cytometry $(n=15)$. Double immunohistochemistry staining of PD-1 and CD68 was also performed to evaluate the correlations among the frequency of PD- $1^{+}$macrophages, clinicopathological characteristics, and prognosis in GC patients $(n=102)$.

Results: The frequency of PD-1 $1^{+}$macrophages was significantly higher in GC tissue than in non-tumor gastric tissue. The phagocytotic activity of PD-1 $1^{+}$macrophages was severely impaired compared with that of PD-1- macrophages. The 5-year disease-specific survival rates in patients with PD- $1^{+}$macrophage ${ }^{\text {Low }}$ (the frequency of PD- $1^{+}$macrophages; $<0.85 \%$ ) and those with PD- $1^{+}$macrophage ${ }^{\text {High }}$ (the frequency of PD- $1^{+}$macrophages; $\left.\geq 0.85 \%\right)$ were 85.9 and $65.8 \%$, respectively $(P=$ 0.008). Finally, multivariate analysis showed the frequency of $\mathrm{PD}-1^{+}$macrophage to be an independent prognostic factor.
\end{abstract}

Conclusions: The function of PD-1 $1^{+}$macrophage was severely impaired and increased frequency of PD $-1^{+}$macrophage worsened the prognosis of GC patients. PD-1-PD-L1 therapies may function through a direct effect on macrophages in GC.

Keywords: Gastric cancer, Macrophage, PD-1, Prognosis, Tumor immunity

\section{Background}

The recent successes of immune checkpoint inhibitors in the treatment of various tumor types clearly indicate that immunotherapy is effective even in patients with cancer. The antibody against programmed cell death 1 (PD-1) is the most clinically successful immune checkpoint drug in the treatment for cancer patients [1-3]. Since PD-1 is closely associated with dysfunction of $\mathrm{CD}_{4}^{+}$and $\mathrm{CD}^{+} \mathrm{T}$ cells, the efficacy of the antibody against PD-1 is widely thought to be attributed to

\footnotetext{
* Correspondence: sai10@tottori-med.jrc.or.jp

${ }^{2}$ Department of Surgery, Japanese Red Cross Tottori Hospital, 117

Shotoku-cho, Tottori 680-8517, Japan

Full list of author information is available at the end of the article
}

activation of $\mathrm{T}$ - cell in the treatment of cancer. However, the detailed mechanisms by which the anti-PD-1 antibody activates immunity against cancer cells have remained unclear.

Macrophages are immune cells belong to the innate immune system. They phagocytose bacteria and other harmful organisms and initiate inflammation by releasing pro- inflammatory mediators. They also present antigens to $\mathrm{T}$ cells and play important roles in cell-mediated immunity. A previous study reported that macrophages express PD-1 during pathogen infection [4-7]. Furthermore, Gordon et al. recently demonstrated that the function of tumor-associated macrophages (TAMs) that express PD-1 was impaired,

C The Author(s). 2020 Open Access This article is distributed under the terms of the Creative Commons Attribution 4.0 International License (http://creativecommons.org/licenses/by/4.0/), which permits unrestricted use, distribution, and 
which resulted in the progression of tumors [8], indicating that PD-1 was involved in the function of macrophages.

Gastric cancer (GC) is the third cause of cancer death worldwide [9]. We previously reported upregulated PD-1 expression on both $\mathrm{CD}^{+}$and $\mathrm{CD}^{+} \mathrm{T}$ cells obtained from cancer tissue in GC patients [10]. The function of these PD-1-positive $\mathrm{CD}^{+}$and $\mathrm{CD}^{+} \mathrm{T}$ cells was impaired, suggesting that increased frequency of $\mathrm{PD}-1^{+} \mathrm{T}$ cells might play important roles in immune evasion of GC patients. Nivolumab, one of anti-PD-1 antibodies, was recently reported to be effective in the treatment of GC [11]. Given the fact that PD-1 expression is upregulated on both $\mathrm{CD}^{+}$and $\mathrm{CD}^{+} \mathrm{T}$ cells, the primary mechanism of the anti-PD-1 antibody in GC patients may be in the regulation of $\mathrm{T}$ cells. However, other effects of the anti-PD-1 antibody remain unclear thus far. It is indispensable to unveil the detailed mechanisms by which anti-PD-1 antibody activate anti-tumor immunity in cancer patients to maximize its effects and develop more effective cancer immunotherapy. Therefore, the current study was undertaken to evaluate PD-1 expression on macrophages in GC tissue and examine its effect on anti-tumor immunity in GC patients.

\section{Methods}

\section{Patients}

This study included gastric adenocarcinoma patients who underwent gastrectomy at Tottori University Hospital (Yonago, Japan). The patients who had preoperative treatment, such as radiotherapy, chemotherapy, or other medical interventions, were excluded. Adjuvant S-1 was performed in 34 patients who had stage II or III GC. The Japanese Classification of Gastric Cancer was used to determine the clinicopathologic findings [12]. This study was approved by the Institutional Review Board at Tottori University Hospital (18A108).

\section{Isolation of tumor-infiltrating mononuclear cells}

Tumor-infiltrating mononuclear cells were isolated from 15 GC patients who underwent gastrectomy as previously described [13]. In brief, fresh cancer tissues and non-cancerous gastric mucosa (at least $5 \mathrm{~cm}$ apart from the tumor in the resected specimen) were cut into small pieces with a size of approximately $1 \mathrm{~mm}$, and digested with $0.002 \%$ DNase I, $0.08 \%$ collagenase IV, and $0.01 \%$ hyaluronidase (all from Worthington, Lakewood, NJ, USA) at $37^{\circ} \mathrm{C}$ for $60 \mathrm{~min}$. After filtering through $70-\mu \mathrm{m}$ cell strainers (BD Falcon, Franklin Lakes, USA), density-gradient centrifugation using FicollPaque (Pharmacia, Uppsala, Sweden) was performed to obtain the mononuclear cells.

\section{Flow cytometry analysis}

The antibodies used in this study are follows: anti-PD-1phycoerythrin (PE) (Biolegend, San Diego, USA), anti-
PD-1-peridinin-chlorophyll-protein complex (PerCP) (Biolegend), anti-CD45-PE-Cyanin 5 (PE-Cy5) (BD PharMingen, San Jose, USA), anti-CD11b-fluorescein isothiocyanate (FITC) (BD PharMingen), anti-CD11bAllophecocyanin (APC) (BD PharMingen), anti-CD11cAPC (BD PharMingen), and anti-CD206-APC (BD PharMingen). The BD LSRFortessa ${ }^{\mathrm{Tm}}$ cell analyzer (BD Biosciences, San Jose, CA, USA) was used for the analysis.

\section{Phagocytosis assay}

CD11b-positive cells were isolated from mononuclear cells obtained from GC tissue using a Magnetic Cell Sorting System (Milteny Biotec, Bergisch Gladbach, Germany). Cells were resuspended into RPMI 1640 (Thermo Fisher Scientific, Tokyo, Japan) in 96 well plate (Corning, NY, USA) and incubated at $37^{\circ} \mathrm{C}$ with Texas red conjugated Zymosan A (FUJIFILM, Tokyo, Japan) for $4 \mathrm{~h}$. After washing with phosphate buffered salts (PBS; FUJIFILM), cells were stained with anti-CD11bFITC, anti-PD-1-PerCP, and DAPI (Cell Biolabs, San Diego, CA, USA). The numbers of $\mathrm{PD}-1^{+}$macrophages that phagocytosed Zymosan A were determined by flow cytometry analysis.

\section{Immunohistochemistry assay}

Immunohistochemistry was carried out using samples from 102 patients with stage I-III gastric adenocarcinoma as previously described [13]. Four $\mu \mathrm{m}$-thick paraffin sections were dewaxed, deparaffinized in xylene, and rehydrated through a graded alcohol series. The sections were boiled for $20 \mathrm{~min}$ in a microwave oven in $10 \mathrm{mM}$ citrate buffer (pH 6.0) to retrieve PD-1 and CD68 antigen. The slides were subsequently incubated with rabbit anti-PD-1 antibody (Clone EPR4877(2), Abcam plc, Cambridge, UK; 1:500 dilution) and mouse anti-CD68 antibody (Clone PG-M1, Dako, Santa Clara, CA, USA; 1:100 dilution) overnight at $4{ }^{\circ} \mathrm{C}$. The slides were then incubated with the conjugated goat anti-mouse polymer horseradish peroxidase (HRP) and the conjugated goat anti-rabbit polymer alkaline phosphatase (AP) secondary antibodies. (MACH 2 double stain ${ }^{\oplus}$ Biocare Medical, Pacheco, CA, USA) for $30 \mathrm{~min}$. Staining was visualized with peroxidase substrate (ImmPACT ${ }^{\bullet}$ DAB; Vector Laboratories, Burlingame, CA) and AP substrate (ImmPACT ${ }^{\oplus}$ Vector $^{\oplus}$ Red; Vector Laboratories), which were visible as brown and red, respectively. The counterstain was then performed using Mayer's hematoxylin solution (FUJIFILM). Images of 3 fields $(\times 200)$, which were randomly selected in a blinded manner, were acquired using a Nikon Eclipse Ts2 microscope (Nikon Instech, Tokyo, Japan). The separation of stains was achieved using the color deconvolution plug in of ImageJ software 1.47 (National Institutes of Health, USA) [14]. Using the cell counter plug in of ImageJ software, the number of stained cells was determined for each 

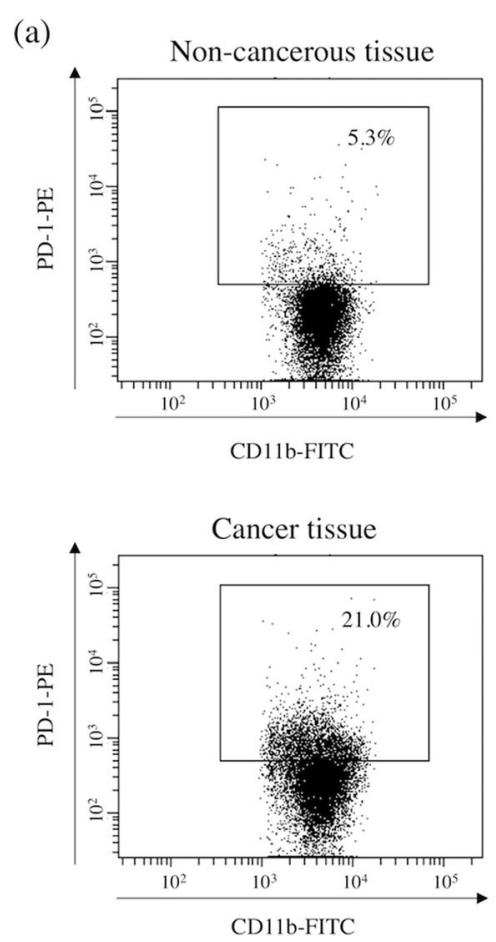

(b)

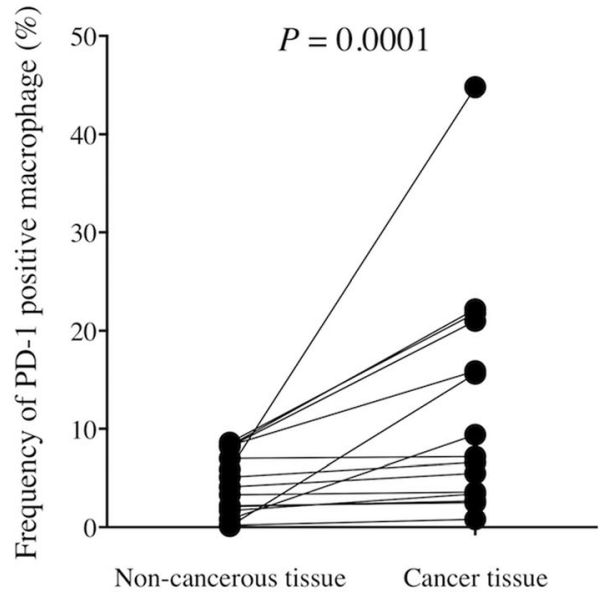

Fig. 1 Presence of PD-1 ${ }^{+}$macrophages in gastric cancer tissue by flow cytometry. a Representative FACS data for PD-1 expression on macrophages obtained from non-cancerous gastric mucosa and gastric cancer tissue. $\mathbf{b}$ PD-1 expression is significantly higher on macrophages obtained from gastric cancer tissue than on those obtained from non-cancerous gastric mucosa $(P=0.0001)$

(a)

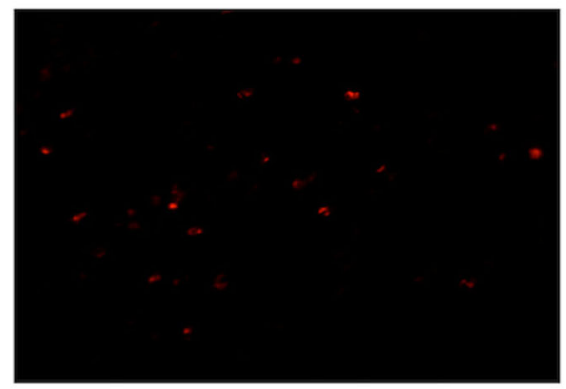

(c)

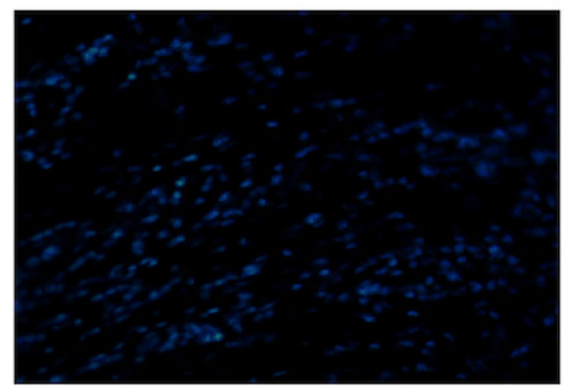

(b)

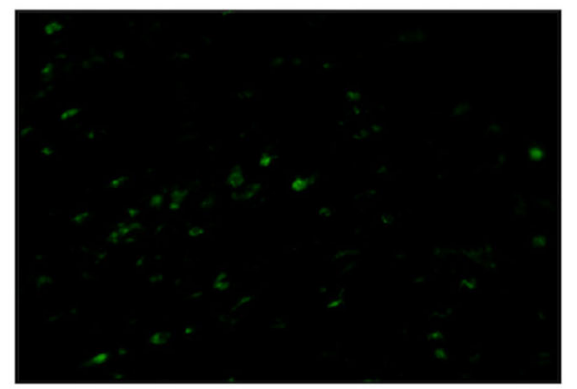

(d)

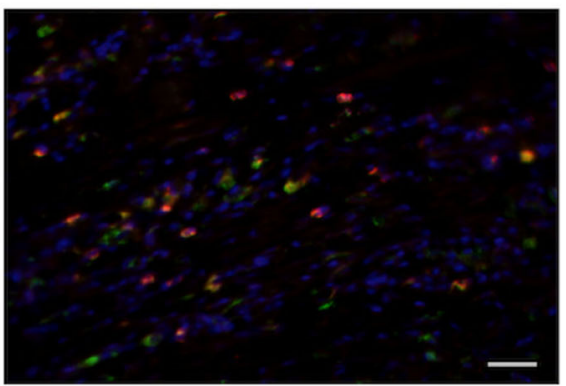

Fig. 2 Presence of $\mathrm{PD}-1^{+}$macrophages in gastric cancer tissue by immunofluorescence staining. Representative images of immunofluorescence staining of gastric cancer tissue for a PD-1, b CD68, c DAPI, and $\mathbf{d}$ merged staining 


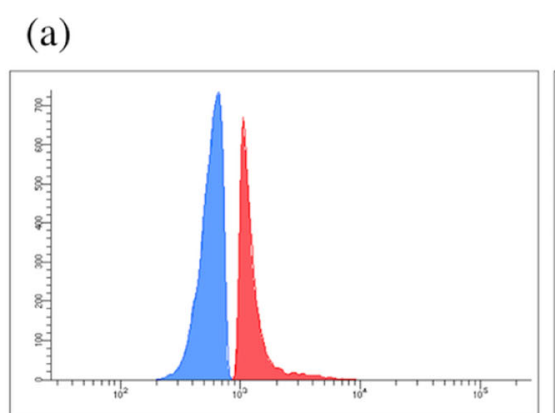

(d)

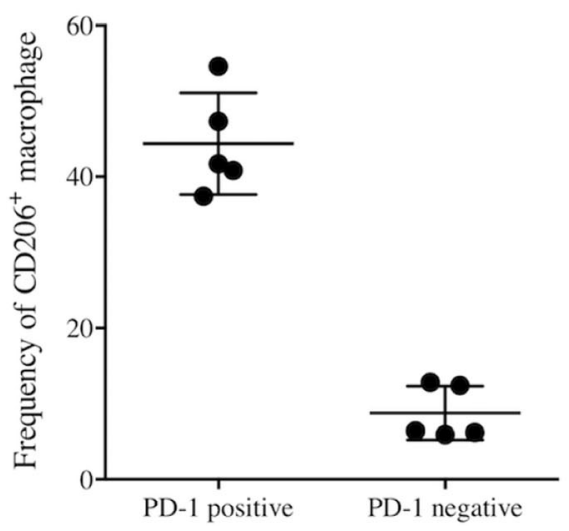

(c)
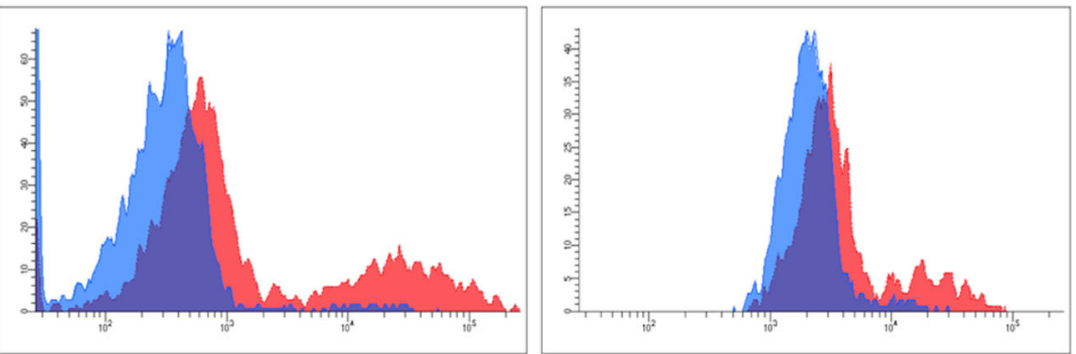

(e)

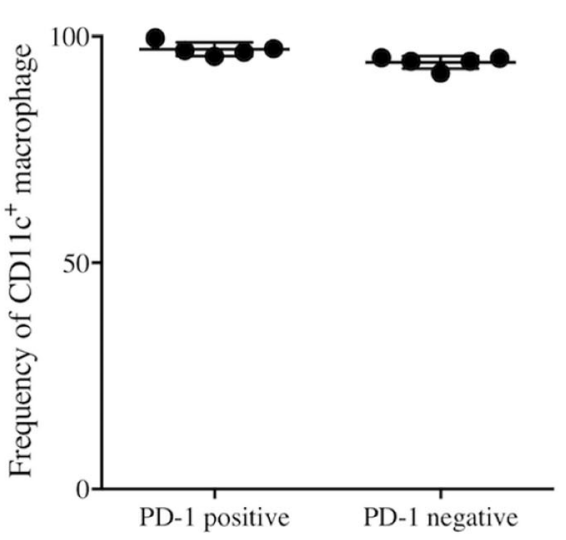

Fig. 3 PD-1 ${ }^{+}$macrophages showed a trend towards the expression of an M2-like profile. Representative flow cytometry histograms showing expression of typical tumor-associated macrophage markers a PD-1; b CD206; $\mathbf{c}$ CD11 in PD-1 ${ }^{-}$versus PD-1 ${ }^{+}$macrophages in gastric cancer tissue $(n=5)$. Representative histograms are shown. Analysis of TAM markers $\mathbf{d}$ CD206; e CD11C in PD- $1^{-}$versus PD-1+ $1^{+}$subsets from GC tissue shows that PD- $1^{+}$macrophages express more CD206 . $n=5$, experiment conducted once. Paired one-tailed t-test

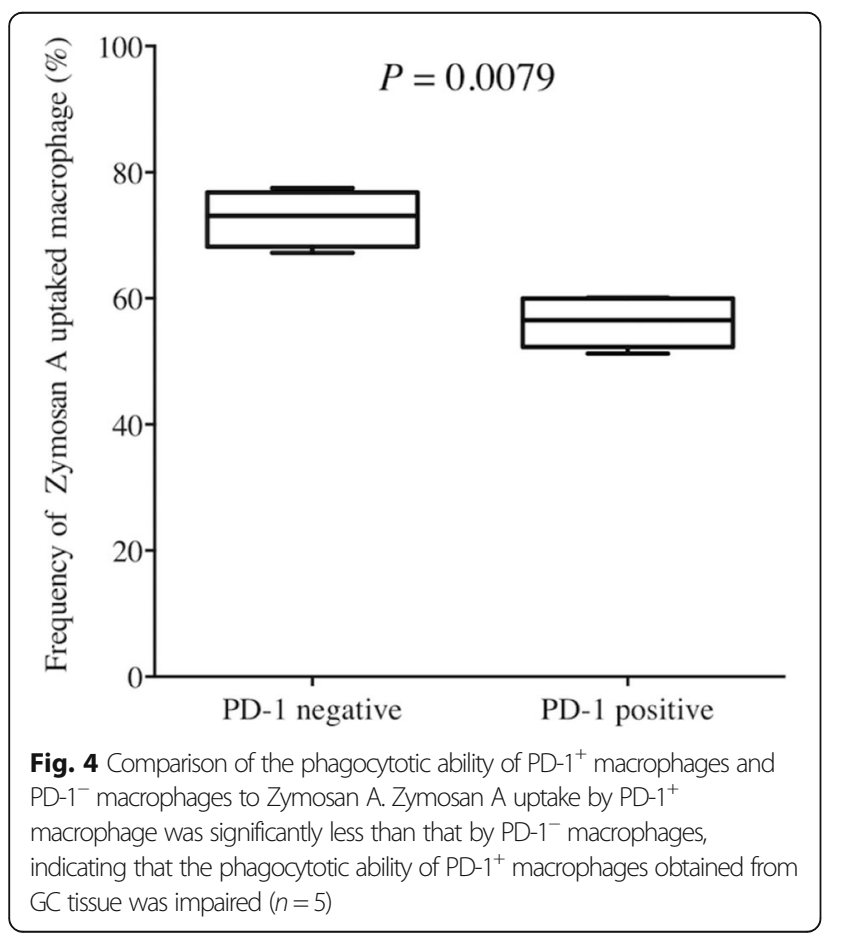

image. The frequency of PD- $1^{+}$macrophages was represented by the ratio of the number of PD $-1^{+} \mathrm{CD} 68^{+}$cells to that of $\mathrm{CD}^{+} 8^{+}$cells.

\section{Immunofluorescence staining}

Immunofluorescence staining for PD-1 and CD68 was performed as previously described [15]. Four $\mu \mathrm{m}$ thick paraffinembedded sections were incubated with primary antibodies, which were the same antibodies used in immunohistochemistry, overnight at $4{ }^{\circ} \mathrm{C}$. The slides were then incubated with Goat Anti-mouse IgG H\&L (Alexa Fluor ${ }^{\circ} 488$ ) and Goat Anti-rabbit IgG H\&L (Alexa Fluor ${ }^{\circ}$ 647) (Abcam plc., Cambridge, UK; 1:500 dilution) for $30 \mathrm{~min}$ at room temperature. After washing with PBS, slides were mounted with ProLong Gold antifade reagent with 4,6-diamidino-2-phenylindole (Thermo Fisher Scientific) and examined using a Nikon Eclipse Ts2 microscope (Nikon Instech).

\section{Statistical analysis}

The differences between the frequency of PD- $1^{+}$macrophages in GC tissue and that in non-cancerous gastric tissue were compared by paired t-test. The differences of clinicopathologic characteristics between two groups were compared by Mann-Whitney U test. Receiver operating 


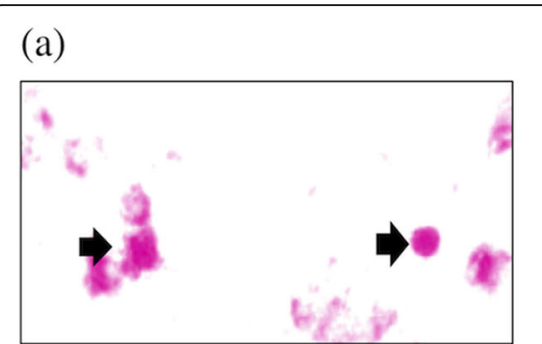

(d)

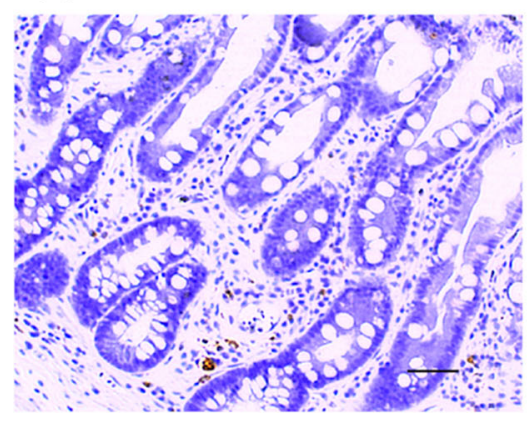

(b)

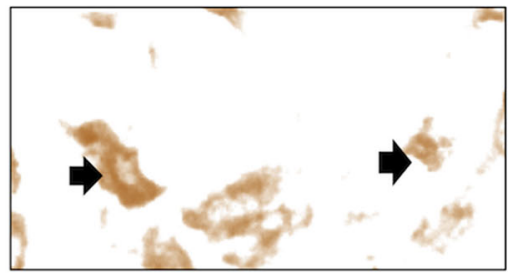

(e)

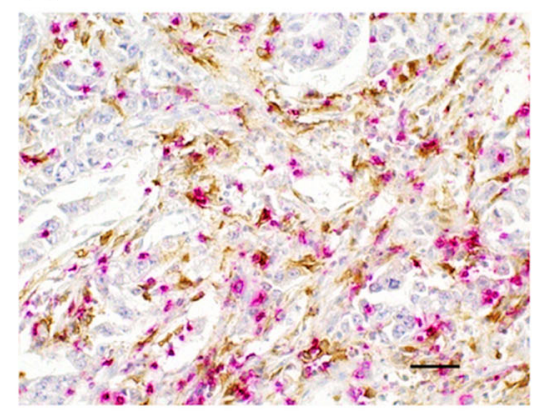

(c)

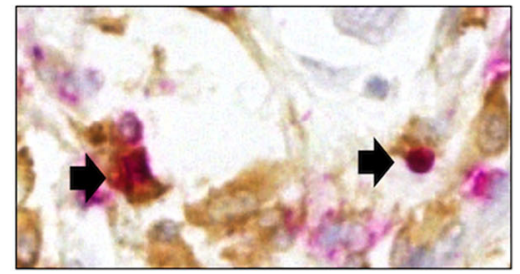

(f)

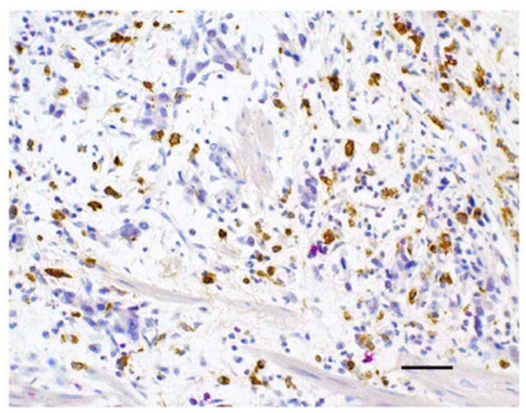

Fig. 5 Presence of PD- $1^{+}$macrophages in normal gastric mucosa and gastric cancer tissue by immunohistochemistry. Representative image of PD- $1^{+}$ macrophages (arrows) in gastric cancer tissue following double staining immunohistochemistry (pink, PD-1; brown, CD68). a PD-1, b CD68, c merge of PD-1 and CD68, d normal gastric mucosa, e gastric cancer tissue - PD-1 ${ }^{+}$macrophage ${ }^{\text {High }}$, (f) gastric cancer tissue - PD- $1^{+}$macrophage ${ }^{\text {Low }}$. Magnification $200 \times$

characteristic (ROC) analysis was used to determine the Youden index. The frequency of PD- $1^{+}$macrophages with the Youden index was used as an optimal cutoff value. Survival rates were calculated using the Kaplan-Meier method and their differences were determined using the log-rank test. Cox's proportional hazards model was used to perform univariate analyses. Cox's proportional hazards model and a stepwise procedure were used for multivariate analyses. A value of $P<0.05$ was considered statistically significant. SPSS statistics version 24 (SPSS Inc., Chicago, IL, USA) and GraphPad Prism version 6 (GraphPad Software, Inc., La Jolla, CA, USA) software were used for all statistical analyses.

\section{Results}

PD-1 ${ }^{+}$macrophages are abundant and functionally impaired in GC tissue

We first determined the frequency of $\mathrm{PD}-1^{+}$macrophages in GC tissue and non-cancerous gastric tissue by flow cytometry $(n=15)$. The frequency of PD- $1^{+}$macrophages was significantly higher in GC tissue than in non-cancerous gastric tissue $(P=0.0001$, Fig. 1). Immunofluorescence staining also confirmed the presence of $\mathrm{PD}-1^{+}$macrophages in GC tissue (Fig. 2). Flow cytometry analysis revealed that $\mathrm{PD}-1^{+}$macrophages in GC tissue express more CD206, indicating that they showed an M2-like profile (Fig. 3). Therefore, PD-1 ${ }^{+}$ macrophages in GC tissue seem to be pro-tumorigenic.
Since a previous study demonstrated that the phagocytotic ability of PD- $1^{+}$macrophages was impaired in colorectal cancer [8], we next determined the phagocytotic ability of both PD- $1^{+}$and PD- $1^{-}$macrophages obtained from GC tissue using Zymosan A. Our results demonstrated that Zymosan A uptake by $\mathrm{PD}-1^{+}$macrophages was significantly less than that by $\mathrm{PD}-1^{-}$macrophages, indicating that the phagocytotic ability of PD $-1^{+}$macrophages obtained from GC tissue was impaired $(P=$ 0.0079, Fig. 4).

\section{Increased number of PD- $1^{+}$macrophages is related to poor prognosis in GC patients}

The immunohistochemistry results revealed that there were PD-1 and CD68 double positive cells (PD- $1^{+}$macrophages) and $\mathrm{PD}-1^{+} \mathrm{CD} 68^{-}$cells, which were likely to be tumorinfiltrating lymphocytes, in GC tissues (Fig. 5). The frequencies of PD- $1^{+}$macrophages in GC tissue and in noncancerous gastric tissue were $2.04 \pm 2.77$ and $0.0547 \pm 0.131$, respectively $(P=0.0001)$, which was consistent with the results by flow cytometry analysis. We then determined the correlations among the percentage of PD- $1^{+}$macrophages, clinicopathological variables and prognosis in GC patients $(n=102)$. The frequency of PD- $1^{+}$macrophages was significantly higher in patients aged 75 and more and those with lymph node metastasis than in patients aged less than 75 $(P=0.036)$ and those without lymph node metastasis $(P<$ 0.001 ), respectively (Table 1 ). 
Table 1 Relationships between the percentage of $\mathrm{PD}-1^{+} \mathrm{CD} 68^{+}$ cell and clinicopathological variables

\begin{tabular}{|c|c|c|}
\hline & PD-1 ${ }^{+}$macrophage (\%) & $P$ value \\
\hline Gender & & 0.24 \\
\hline Male $(n=75)$ & $2.40( \pm 4.15)$ & \\
\hline Female $(n=27)$ & $1.24( \pm 2.45)$ & \\
\hline Age & & 0.036 \\
\hline$\geq 75(n=36)$ & $3.31( \pm 4.93)$ & \\
\hline$<75(n=66)$ & $1.42( \pm 2.83)$ & \\
\hline Depth of invasion ${ }^{a}$ & & 0.86 \\
\hline $\mathrm{T} 1(n=12)$ & $3.04( \pm 5.18)$ & \\
\hline T2-4 $(n=90)$ & $1.96( \pm 3.60)$ & \\
\hline Lymph node metastasis & & $<0.001$ \\
\hline Absent $(n=54)$ & $0.54( \pm 1.19)$ & \\
\hline Present $(n=48)$ & $3.83( \pm 4.86)$ & \\
\hline Tumor size & & 0.14 \\
\hline$\geq 4 \mathrm{~cm}(n=60)$ & $2.48( \pm 3.97)$ & \\
\hline$<4 \mathrm{~cm}(n=42)$ & $1.53( \pm 3.51)$ & \\
\hline Histology ${ }^{b}$ & & 0.47 \\
\hline Differentiated $(n=54)$ & $2.22( \pm 3.93)$ & \\
\hline Undifferentiated $(n=48)$ & $1.95( \pm 3.68)$ & \\
\hline Lymphatic invasion & & 0.063 \\
\hline Absent $(n=12)$ & $0.47( \pm 1.20)$ & \\
\hline Present $(n=90)$ & $2.30( \pm 3.97)$ & \\
\hline Venous invasion & & 0.089 \\
\hline Absent $(n=17)$ & $0.93( \pm 2.11)$ & \\
\hline Present $(n=85)$ & $2.32( \pm 4.02)$ & \\
\hline
\end{tabular}

All results expressed as mean $\pm S D$

${ }^{a}$ Depth of invasion: T1: tumor has invaded lamina propria or submucosa; T2: tumor has invaded the muscularis propria; T3: tumor has invaded the subserosa; T4: tumor invasion is contiguous to, or exposed beyond, the serosa or has invaded adjacent structures bifferentiated, papillary, or tubular adenocarcinoma; undifferentiated, poorly differentiated, mucinous adenocarcinoma, and signet-ring cell carcinoma

ROC analysis indicated an optimal cutoff value with Youden index was $0.85 \%$. Patients were then divided into PD- $1^{+}$macrophage (MAC) ${ }^{\text {Low }}(<0.85 \%)$ and PD $-1^{+}$ $\mathrm{MAC}^{\text {High }}(\geq 0.85 \%)$ groups. Five-year disease-specific survival rates were also significantly higher in the PD- $1^{+}$ $\mathrm{MAC}^{\text {Low }}$ group compared with the PD-1 ${ }^{+} \mathrm{MAC}^{\text {High }}$ group, at 85.9 and $65.8 \%$, respectively $(P=0.008$, Fig. 6$)$. Univariate analysis revealed that lymph node metastasis, tumor size, and the frequency of $\mathrm{PD}-1^{+}$macrophages were prognostic factors (Table 2). Finally, multivariate analysis revealed that the frequency of $\mathrm{PD}-1^{+}$macrophages and tumor size were independent prognostic factors in GC patients (Table 2).

\section{Discussion}

We have demonstrated that certain portion of macrophages in GC tumor tissues express PD-1 in this study.

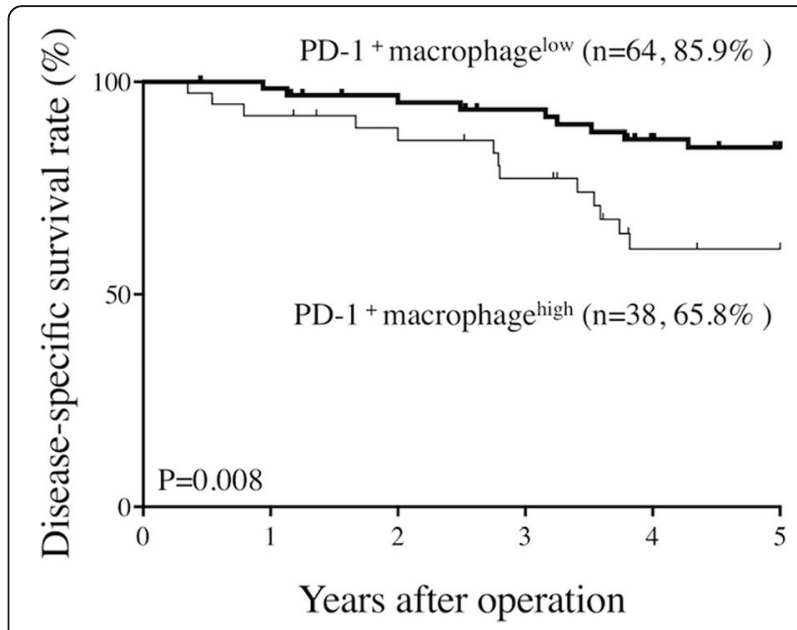

Fig. 6 The prognosis of gastric cancer patients according to the frequency of PD-1 ${ }^{+}$macrophages. Five-year disease-specific sunvival rate of gastric cancer patients with a marked infiltration of PD-1 ${ }^{+}$macrophages was significantly lower than that of those with a slight infiltration of PD-1 ${ }^{+}$macrophages

The frequency of $\mathrm{PD}-1^{+}$macrophages was more abundant in GC tissue than in non-cancerous gastric mucosa, suggesting the possibility that $\mathrm{PD}-1^{+}$macrophages might play some important roles in the progression of GC. The frequency of PD- $1^{+}$macrophages by flow cytometry was more than that by immunohistochemistry in this study, possibly due to the different way of evaluation. PD-1 was first discovered as a molecule expressed on $\mathrm{T}$ cells that induced apoptosis of $\mathrm{T}$ cells [16] and then was identified as a co-signaling molecule by Honjo et al. [17]. PD-1 binds to either of its two ligands, PD-L1 or PD-L2, and delivers a co-inhibitory signal in $\mathrm{T}$ cells indicating that PD-1 negatively controls the function of T cells [17]. Although this molecule plays important roles in preventing hyperactivation of $\mathrm{T}$ cells, which is harmful for the host, it seems to be closely associated with immune evasion observed in chronic infections and tumors. In acute infections, PD-1 is upregulated upon T cell activation. After resolution of the infection, PD-1 expression on T cells decreases and $\mathrm{T}$ cells become memory $\mathrm{T}$ cells [18]. However, there are many exhausted viral-specific $\mathrm{CD}^{+} \mathrm{T}$ cells with high $\mathrm{PD}-1$ expression in chronic human infections with HIV, HBV, and $\mathrm{HCV}$. Although the function of these $\mathrm{CD}^{+} \mathrm{T}$ cells are severely impaired, recent work has shown that blockade of the PD-1 pathway can recover their function in vitro [19]. Furthermore, it was reported that tumor-infiltrating $\mathrm{CD}^{+}$ $\mathrm{T}$ cells specific for tumor antigen, NY-ESO-1, increased PD-1 expression and their function was impaired in ovarian cancer patients [20]. In this regard, we previously reported that PD- 1 expression on both $\mathrm{CD}^{+}$and $\mathrm{CD}^{+} \mathrm{T}$ cells obtained from cancer tissue was upregulated in GC patients and the function of these PD-1-positive $\mathrm{CD}^{+}$and $\mathrm{CD}^{+} \mathrm{T}$ cells was severely impaired. Furthermore, immunohistochemistry showed many $\mathrm{PD}-1^{+} \mathrm{CD} 68^{-}$tumor infiltrating 
Table 2 Univariate and multivariate analyses of prognostic factors associated with disease-specific survival

\begin{tabular}{|c|c|c|c|c|c|c|}
\hline \multirow[t]{2}{*}{ Variables } & \multicolumn{3}{|c|}{ Univariate analysis } & \multicolumn{3}{|c|}{ Multivariate analysis } \\
\hline & $P$ value & $\mathrm{HR}$ & $95 \% \mathrm{Cl}$ & $P$ value & $H R$ & $95 \% \mathrm{Cl}$ \\
\hline Age ( $\geq 75$ vs. $<75)$ & 0.53 & 1.293 & $0.578-2.895$ & & & \\
\hline Gender (female vs. male) & 0.29 & 0.578 & $0.222-1.557$ & & & \\
\hline Tumor size ( $\geq 4 \mathrm{~cm}$ vs. $<4 \mathrm{~cm}$ ) & 0.004 & 4.111 & $1.553-10.879$ & 0.010 & 5.001 & $1.470-17.008$ \\
\hline Lymph node metastasis (present vs. absent) & 0.010 & 2.864 & $1.284-6.388$ & 0.21 & 1.843 & $0.701-4.841$ \\
\hline Lymphatic invasion (present vs. absent) & 0.17 & 4.117 & $0.558-30.378$ & & & \\
\hline Venous invasion (present vs. absent) & 0.063 & 6.679 & $0.905-49.289$ & & & \\
\hline Depth of invasion (T1 vs. T2-4) & 0.64 & 1.415 & $0.334-5.993$ & & & \\
\hline Histology (undifferentiated vs. differentiated) & 0.61 & 1.220 & $0.564-2.640$ & & & \\
\hline PD-1+ CD68+ cell frequency (high vs. low) & 0.008 & 2.971 & $1.369-8.131$ & 0.031 & 2.560 & $1.087-6.026$ \\
\hline S-1 adjuvant chemotherapy (absent vs. present) & 0.022 & 2.671 & $1.154-6.182$ & 0.16 & 1.546 & $0.581-4.116$ \\
\hline
\end{tabular}

See Table 1 for the detail of depth of invasion and histology

Cl Confidence interval

$H R$ Hazard ratio

cells, which were likely lymphocytes, in this study. These suggest that PD-1 expression on $\mathrm{T}$ cells is also related to immune evasion in cancer patients, including GC patients. Although most studies regarding immune evasion by PD-1 have focused on $\mathrm{T}$ cells, recent reports have demonstrated that other immune cells also express PD-1.

Natural killer (NK) cells paly important roles in the eradiation of cancer cells [21-23]. PD-1 overexpression was observed on peripheral and tumor-infiltrating NK cells from patients with digestive cancers including gastric cancer [24]. Blockade of the PD-1 pathway markedly enhances their cytokine production and suppresses their apoptosis, indicating that increased PD-1 expression was closely associated with dysfunction of NK cells. Furthermore, Xiao et al. recently identified a novel pro-tumorigenic B-cell subset with high PD-1 expression in human hepatocellular carcinoma. PD-1 ${ }^{\text {high }}$ B cells impaired the function of T-cell, which resulted in disease progression, via IL10-dependent pathways upon interacting with PD-L1 [25]. Overall, PD-1 overexpression on not only $\mathrm{T}$ cells but also other types of immune cells seems to be closely related to immune evasion observed in cancer patients.

Macrophages are typically divided into M1 and M2 phenotypes. M1-type macrophages kill target cells and produce inflammatory cytokines, indicating that they are anti-tumorigenic, whereas M2-type macrophages reduce inflammatory responses and adaptive Th1 immunity, indicating that they are pro-tumorigenic [26-29]. It has been demonstrated that TAMs polarize into the M2 phenotype and suppress the host immune responses against cancers, which results in tumor progression. Therefore, the presence of TAMs worsens prognosis in human cancers [30]. Our results revealed that PD-1 ${ }^{+}$ macrophages showed an M2-like profile, indicating that PD- $1^{+}$macrophages are pro-tumorigenic. Our results further showed that the phagocytotic ability of PD-1 $1^{+}$ macrophages was impaired compared with $\mathrm{PD}-1^{-}$macrophages. The phagocytotic ability of macrophages plays an important role in preventing tumor progression. Therefore, it is likely that impaired phagocytotic ability of $\mathrm{PD}-1^{+}$macrophages observed in the current study promotes tumor progression. In this regard, we also showed that the prognosis of GC patients with PD- $1^{+}$ $\mathrm{MAC}^{\text {High }}$ was significantly worse than that of GC patients with $\mathrm{PD}-1^{+} \mathrm{MAC}^{\mathrm{Low}}$. Furthermore, multivariate analysis revealed that the frequency of $\mathrm{PD}-1^{+}$macrophage was an independent prognostic indicator, indicating that the frequency of PD- $1^{+}$macrophage was closely associated with prognosis of gastric cancer patients regardless of stage of disease. Considering the close correlation between the frequency of PD- $1^{+}$macrophages and prognosis of GC patients, a therapeutic strategy targeting the phagocytotic activity of macrophages might be effective for the treatment of GC patients.

PD-1 binds to either PD-L1 or PD-L2, and delivers a co-inhibitory signal. We previously demonstrated that a certain proportion of GC cells expressed PD-L1 [31], indicating that PD-1 is able to deliver co-inhibitory signals in $\mathrm{PD}-1^{+}$macrophages in GC patients.

Epstein-Barr virus (EBV) is an oncogenic human herpesvirus involved in the development of around $10 \%$ of GC. The overexpression of PD-L1 is one of the features of EBVassociated GC. Recent study demonstrated that EBVassociated gastric cancer cells expressing high levels of PDL1 suppress T-cell proliferation [32]. Furthermore, PD-L1 expression on tumor-infiltrating immune cells was reported to be associated with distinct clinicopathological features, including high densities of tumor-infiltrating lymphocytes, mismatch repair deficiency, and EBV positivity in GC [33]. Helicobacter pylori infection, known as the strongest risk factor for GC, was also significantly associated with expression of PD-L1 and PD-1 [34]. However, the correlations 
among the frequency of PD- $1^{+}$macrophages, mismatch repair deficiency, and EBV and Helicobacter pylori infection remains unclear in this study. Therefore, further investigations are urgently required to unveil them.

\section{Conclusions}

Our results suggest that PD-1 expression on macrophages is closely associated with their dysfunction in GC. Considering that upregulated PD-1 expression on macrophages is associated with poor prognosis, therapies targeting PD-1 pathway may function through a direct effect on not only $\mathrm{T}$ cells but also macrophages in GC.

\section{Abbreviations}

CD: Cluster of differentiation; CSF: Colony stimulating factor; DSS: Diseasespecific survival; EBV: Epstein-Barr virus; FITC: Fluorescein isothiocyanate; GC: Gastric cancer; HBV: Hepatitis B virus; HCV: Hepatitis C virus; HIV: Human immunodeficiency virus; IL: Interleukin; MAC: Macrophage; NK: Natural killer; PBS: Phosphate buffered salts; PD-1: Programmed cell death 1; PerCP: Peridinin chlorophyll protein; RPMI: Roswell Park Memorial Institute; ROC: Receiver operating characteristic; TAMs: Tumor-associated macrophages

\section{Acknowledgements}

We thank Edanz Group (mww.edanzediting.com/ac) for editing a draft of this manuscript.

\section{Authors' contributions}

YK and HS participated in the design of the study, interpretation of data, analysis, and drafting the article. YK, WM, SS, YM, YS, KM, TM, YF1, YN, CS, and KH carried out experiments. YF2 revised the article. All authors approved the final version of the article.

\section{Funding}

The authors received no grants, equipment or funding for this study.

\section{Availability of data and materials}

The datasets used and/or analysed during the current study are available from the corresponding author on reasonable request.

\section{Ethics approval and consent to participate}

All procedures followed were in accordance with the ethical standards of the responsible committee on human experimentation (institutional and national) and with the Helsinki Declaration of 1964 and later versions. Written informed consent to be included in the study was obtained from all patients.

\section{Consent for publication}

Not applicable.

\section{Competing interests}

The authors declare that they have no competing interests.

\section{Author details}

'Division of Surgical Oncology, Department of Surgery, School of Medicine, Tottori University Faculty of Medicine, 36-1 Nishi-cho, Yonago 683-8504, Japan. ${ }^{2}$ Department of Surgery, Japanese Red Cross Tottori Hospital, 117 Shotoku-cho, Tottori 680-8517, Japan. ${ }^{3}$ Division of Radioisotope Science, Research, Initiative Center, Organization for Research Initiative and Promotion, Tottori University, 86 Nishi-cho, Yonago City, Tottori 683-8503, Japan. ${ }^{4}$ Division of Molecular Biology, Department of Molecular and Cellular Biology, School of Life Science, Faculty of Medicine, Tottori University, 86 Nishi-cho, Yonago, Tottori 683-8503, Japan.

Received: 17 October 2019 Accepted: 13 February 2020 Published online: 04 March 2020

\section{References}

1. Kato K, Cho BC, Takahashi M, Okada M, Lin CY, Chin K, et al. Nivolumab versus chemotherapy in patients with advanced oesophageal squamous cell carcinoma refractory or intolerant to previous chemotherapy (ATTR
ACTION-3): a multicentre, randomised, open-label, phase 3 trial. Lancet Oncol. 2019;20(11):1506-17.

2. Carbone DP, Reck M, Paz-Ares L, Creelan B, Horn L, Steins M, et al. First-line Nivolumab in stage IV or recurrent non-small-cell lung Cancer. N Engl J Med. 2017;376(25):2415-26.

3. Bellmunt J, de Wit R, Vaughn DJ, Fradet Y, Lee JL, Fong L, et al. Pembrolizumab as second-line therapy for advanced Urothelial carcinoma. N Engl J Med. 2017;376(11):1015-26.

4. Huang $X$, Venet F, Wang YL, Lepape A, Yuan Z, Chen Y, et al. PD-1 expression by macrophages plays a pathologic role in altering microbial clearance and the innate inflammatory response to sepsis. Proc Natl Acad Sci U S A. 2009;106(15):6303-8.

5. Bally AP, Lu P, Tang Y, Austin JW, Scharer CD, Ahmed R, et al. NF-kappaB regulates PD-1 expression in macrophages. J Immunol. 2015;194(9):4545-54.

6. Chen W, Wang J, Jia L, Liu J, Tian Y. Attenuation of the programmed cell death-1 pathway increases the M1 polarization of macrophages induced by zymosan. Cell Death Dis. 2016;7:e2115.

7. Shen L, Gao Y, Liu Y, Zhang B, Liu Q, Wu J, et al. PD-1/PD-L pathway inhibits M.tb-specific CD4(+) T-cell functions and phagocytosis of macrophages in active tuberculosis. Sci Rep. 2016;6:38362.

8. Gordon SR, Maute RL, Dulken BW, Hutter G, George BM, McCracken MN, et al. PD-1 expression by tumour-associated macrophages inhibits phagocytosis and tumour immunity. Nature. 2017;545(7655):495-9.

9. Bray F, Ferlay J, Soerjomataram I, Siegel RL, Torre LA, Jemal A. Global cancer statistics 2018: GLOBOCAN estimates of incidence and mortality worldwide for 36 cancers in 185 countries. CA Cancer J Clin. 2018;68(6):394-424.

10. Saito H, Kuroda H, Matsunaga T, Osaki T, Ikeguchi M. Increased PD-1 expression on CD4+ and CD8+ T cells is involved in immune evasion in gastric cancer. J Surg Oncol. 2013;107(5):517-22.

11. Kang YK, Boku N, Satoh T, Ryu MH, Chao Y, Kato K, et al. Nivolumab in patients with advanced gastric or gastro-oesophageal junction cancer refractory to, or intolerant of, at least two previous chemotherapy regimens (ONO-4538-12, ATTRACTION-2): a randomised, double-blind, placebo-controlled, phase 3 trial. Lancet (London, England). 2017;390(10111):2461-71.

12. Japanese Gastric Cancer Association. Japanese classification of gastric carcinoma: 3rd English edition. Gastric Cancer. 2011;14(2):101-12.

13. Murakami Y, Saito H, Shimizu S, Kono Y, Shishido Y, Miyatani K, et al. Increased regulatory $B$ cells are involved in immune evasion in patients with gastric cancer. Sci Rep. 2019;9(1):13083.

14. Ruifrok AC, Johnston DA. Quantification of histochemical staining by color deconvolution. Anal Quant Cytol Histol. 2001;23(4):291-9.

15. Miyatani K, Saito H, Murakami Y, Watanabe J, Kuroda H, Matsunaga T, et al. A high number of lgG4-positive cells in gastric cancer tissue is associated with tumor progression and poor prognosis. Virchows Arch. 2016;468(5):549-57.

16. Ishida Y, Agata Y, Shibahara K, Honjo T. Induced expression of PD-1, a novel member of the immunoglobulin gene superfamily, upon programmed cell death. EMBO J. 1992;11(11):3887-95.

17. Freeman GJ, Long AJ, Iwai Y, Bourque K, Chernova T, Nishimura $\mathrm{H}$, et al. Engagement of the PD-1 immunoinhibitory receptor by a novel B7 family member leads to negative regulation of lymphocyte activation. J Exp Med. 2000;192(7):1027-34

18. Barber DL, Wherry EJ, Masopust D, Zhu B, Allison JP, Sharpe AH, et al. Restoring function in exhausted CD8 T cells during chronic viral infection. Nature. 2006;439(7077):682-7.

19. Keir ME, Butte MJ, Freeman GJ, Sharpe AH. PD-1 and its ligands in tolerance and immunity. Annu Rev Immunol. 2008;26:677-704.

20. Matsuzaki J, Gnjatic S, Mhawech-Fauceglia P, Beck A, Miller A, Tsuji T, et al. Tumorinfiltrating NY-ESO-1-specific CD8+ T cells are negatively regulated by LAG-3 and PD-1 in human ovarian cancer. Proc Natl Acad Sci U S A. 2010:107(17):7875-80.

21. Nunn ME, Herberman RB. Natural cytotoxicity of mouse, rat, and human lymphocytes against heterologous target cells. J Natl Cancer Inst. 1979;62(4):765-71.

22. Vose BM, Moore M. Natural cytotoxicity in humans: susceptibility of freshly isolatd tumor cells to lysis. J Natl Cancer Inst. 1980;65(2):257-63.

23. Uchida A, Yanagawa E. Natural killer cell activity and autologous tumor killing activity in cancer patients: overlapping involvement of effector cells as determined in two-target conjugate cytotoxicity assay. J Natl Cancer Inst. 1984;73(5):1093-100

24. Liu Y, Cheng Y, Xu Y, Wang Z, Du X, Li C, et al. Increased expression of programmed cell death protein 1 on NK cells inhibits NK-cell-mediated antitumor function and indicates poor prognosis in digestive cancers. Oncogene. 2017;36(44):6143-53. 
25. Xiao X, Lao XM, Chen MM, Liu RX, Wei Y, Ouyang FZ, et al. PD-1hi identifies a novel regulatory B-cell population in human Hepatoma that promotes disease progression. Cancer Discov. 2016;6(5):546-59.

26. Mantovani A, Sozzani S, Locati M, Allavena P, Sica A. Macrophage polarization: tumor-associated macrophages as a paradigm for polarized M2 mononuclear phagocytes. Trends Immunol. 2002;23(11):549-55.

27. Murray PJ, Allen JE, Biswas SK, Fisher EA, Gilroy DW, Goerdt S, et al. Macrophage activation and polarization: nomenclature and experimental guidelines. Immunity. 2014;41(1):14-20.

28. Heusinkveld M, van der Burg SH. Identification and manipulation of tumor associated macrophages in human cancers. J Transl Med. 2011;9:216.

29. Sica A, Schioppa T, Mantovani A, Allavena P. Tumour-associated macrophages are a distinct M2 polarised population promoting tumour progression: potential targets of anti-cancer therapy. Eur J Cancer (Oxford, England: 1990). 2006;42(6):717-27.0.

30. Pollard JW. Tumour-educated macrophages promote tumour progression and metastasis. Nat Rev Cancer. 2004:4(1):71-8.

31. Saito H, Kono Y, Murakami Y, Shishido Y, Kuroda H, Matsunaga T, et al. Highly activated PD-1/PD-L1 pathway in gastric Cancer with PD-L1 expression. Anticancer Res. 2018;38(1):107-12.

32. Sasaki S, Nishikawa J, Sakai K, lizasa H, Yoshiyama H, Yanagihara M, et al. EBV-associated gastric cancer evades T-cell immunity by PD-1/PD-L1 interactions. Gastric Cancer. 2019;22(3):486-96.

33. Kawazoe A, Kuwata T, Kuboki Y, Shitara K, Nagatsuma AK, Aizawa M, et al. Clinicopathological features of programmed death ligand 1 expression with tumor-infiltrating lymphocyte, mismatch repair, and Epstein-Barr virus status in a large cohort of gastric cancer patients. Gastric Cancer. 2017;20(3):407-15.

34. Shen B, Qian A, Lao W, Li W, Chen X, Zhang B, et al. Relationship between helicobacter pylori and expression of programmed death-1 and its ligand in gastric intraepithelial neoplasia and early-stage gastric cancer. Cancer Manag Res. 2019;11:3909-19.

\section{Publisher's Note}

Springer Nature remains neutral with regard to jurisdictional claims in published maps and institutional affiliations.

Ready to submit your research? Choose BMC and benefit from:

- fast, convenient online submission

- thorough peer review by experienced researchers in your field

- rapid publication on acceptance

- support for research data, including large and complex data types

- gold Open Access which fosters wider collaboration and increased citations

- maximum visibility for your research: over $100 \mathrm{M}$ website views per year

At $\mathrm{BMC}$, research is always in progress.

Learn more biomedcentral.com/submissions 